\title{
Distal Interphalangeal Joint 3 of the Hand
}

National Cancer Institute

\section{Source}

National Cancer Institute. Distal Interphalangeal Joint 3 of the Hand. NCI Thesaurus.

Code C114189.

A ginglymoid (hinge) synovial joint within the third dig it of the hand connecting the middle and distal phalanges. 